\title{
Malondialdehyde (MDA) and superoxide dismutase (SOD) levels - distinguishing parameters between benign and malignant pleural effusions
}

\author{
Qazi Najeeb, ${ }^{1 *}$ Neeru Bhaskar, ${ }^{1}$ Imran Masood, ${ }^{2}$ Sanchit Wadhwa, ${ }^{3}$ Harnam Kaur, ${ }^{1}$ Sheikh Ishaq ${ }^{1}$ \\ ${ }^{*}$ Department of Biochemistry, Maharishi Markandeshwar Institute of Medical Science \& Research, Mullana, \\ Ambala, Haryana, India. \\ ${ }^{2}$ Department of Internal Medicine, Markandeshwar Institute of Medical Science \& Research, Mullana, Ambala, Haryana, India. \\ ${ }^{3}$ Department of Respiratory Medicine, Markandeshwar Institute of Medical Science \& Research, Mullana, Ambala, Haryana, India.
}

\begin{abstract}
Introduction: Pleural effusion is a common clinical disorder and is either a manifestation or a complication of one or other respiratory or non-respiratory diseases. Increased oxidative stress participates in the pathogenesis of both airways and parenchymal lung diseases. There is a critical balance between free radical generation and antioxidant defences. The local production of free radicals and the role of oxidative stress in the pathogenesis of pleural effusions have not been extensively studied. Objective: To assess the levels of malondialdehyde (MDA), superoxide dismutase (SOD), total proteins (TPR) and lactate dehydrogenase (LDH) in pleural fluid and serum, also to analyse that whether malondialdehyde and superoxide dismutase can be used as potential markers for distinguishing between benign and malignant pleural effusion. Research Design and Methods: 96 participants were included in this prospective study and were divided into two groups. Group-I consisted of 48 cases of malignant pleural effusion and group-II consisted of 48 cases of benign pleural effusion. Results: Mean serum levels of malondialdehyde, superoxide dismutase, lactate dehydrogenase and total proteins in malignant (group-I) were $131.88 \pm 12.17 \mathrm{nmol} / \mathrm{ml}, 39.28 \pm 5.28 \mathrm{U} / \mathrm{ml}, 285.20 \pm 33.06 \mathrm{IU} / \mathrm{L}, 6.0 \pm 0.67 \mathrm{gm} \%$ and in benign (group-II) were $72.83 \pm 5.58 \mathrm{nmol} / \mathrm{ml}, 34.35 \pm 3.61 \mathrm{U} / \mathrm{ml}, 227.69 \pm 10.01 \mathrm{IU} / \mathrm{L}, 6.13 \pm 0.58 \mathrm{gm} \%$ respectively. In pleural fluid mean levels of malondialdehyde, superoxide dismutase, lactate dehydrogenase and total proteins malignant pleural effusion (group-I) were $126.83 \pm 12.26 \mathrm{nmol} / \mathrm{ml}, 38.63 \pm 5.67 \mathrm{U} / \mathrm{ml}, 185.28 \pm 21.48 \mathrm{IU} / \mathrm{L}, 4.34 \pm 0.84 \mathrm{gm} \%$ and in benign pleural effusion (group-II) were $53.01 \pm 8.92 \mathrm{nmol} / \mathrm{ml}, 32.21 \pm 3.27 \mathrm{U} / \mathrm{ml}, 120.29 \pm 15.37 \mathrm{IU} / \mathrm{L}$, $4.12 \pm 0.47 \mathrm{gm} \%$ respectively. This study showed statistically significant increase in malondialdehyde levels ( $\mathrm{p}$-value $<0.001$ ), activities of superoxide dismutase enzymes ( $\mathrm{p}$-value $<0.001$ ) and lactate dehydrogenase levels (p-value $<0.001$ ) in malignant pleural fluids when compared to the benign pleural fluids. Non significant change was observed in total protein levels ( $p$-value $>0.01$ ) in malignant pleural fluids when compared to the benign pleural fluids. Conclusion: Oxidative stress is increased in malignant pleural effusion malondialdehyde and superoxide dismutase being oxidative stress markers, can be used for differentiating between malignant and benign pleural effusions.
\end{abstract}

Keywords: Pleural effusion, malondialdehyde, superoxide dismutase, lactate dehydrogenase.

${ }^{*}$ Corresponding address:

P.G Department of Biochemistry Markandeshwar Institute of Medical Science \& Research, Mullana, Ambala, Haryana, India. India. 133207

Phone: +91-9729939070. Landline: 01731-304553

E-mail: qnajeeb@gmail.com

DOI: $10.5530 / a x .2012 .2 .2$

\section{INTRODUCTION}

Pleural effusion is a common clinical disorder and is either a manifestation or a complication of one or other respiratory or non-respiratory diseases. It heralds a serious prognosis if not diagnosed or treated properly. Approximately one million patients develop pleural effusion each year. ${ }^{[1]}$ Free radical generation and antioxidant defences are well 
Qazi Najeeb, et al.: Malondialdehyde (MDA) and superoxide dismutase (SOD) levels

balanced. It has been suggested that oxidative stress may be associated with many pulmonary disorders including malignancy. ${ }^{[2]}$ Oxidative stress is defined as the imbalance between oxidants and antioxidants. ${ }^{[3]}$

Lipid peroxidation is a chain reaction providing a continuous supply of free radicals as it involves the oxidation of polyunsaturated fatty acids in membranes causing oxidative cell damage. MDA (thiobarbituric acid reacting substance) is formed as an end product of lipid peroxidation and acts as an indicator of it..$^{[4,5]}$ During pulmonary inflammation, increased amounts of Reactive Oxygen Species (ROS) and Reactive Nitrogen Intermediates (RNI) are produced as a result of phagocytic respiratory burst. ${ }^{[6]}$ The primary target of ROS is presumed to be cellular DNA. ROS may act as carcinogenic agents by inducing structural changes in DNA and modulating expression of stress related genes. ${ }^{[7]}$ In animal models, antioxidant molecules have been shown to inhibit experimental carcinogenesis. Not much is known about the respiratory tract antioxidant defences of patients with lung cancer, although superoxide dismutase (SOD) has been proven to prevent carcinogenesis in vitro. ${ }^{[8]}$ Superoxide dismutase (SOD) is a primary enzymatic defence system, which catalyses dismutation of superoxide radicals to hydrogen peroxide and protects body against the potential damage from superoxide radicals. ${ }^{[9]}$

The local production of free radicals and the role of oxidative stress in the pathogenesis of pleural effusions have not been extensively studied. So the aim of the present study was to assess the levels of MDA, SOD, total proteins and lactate dehydrogenase (LDH) in pleural fluid and serum, also to analyse that whether MDA and SOD can be used as a potential marker for distinguishing between benign and malignant pleural effusion.

\section{MATERIAL AND METHODS}

This cross-sectional study was conducted in the Department of Biochemistry in collaboration with Department of Internal Medicine and Respiratory Medicine of Maharishi Markandeshwar Institute of Medical Science and Research, Mullana, Ambala for a period of one year. Total 96 patients with pleural effusion were included and were grouped based on the histo-pathological analysis:
1. Group-I
Malignant pleural effusion.
2. Group-II
Benign pleural effusion.

The present study was approved by the ethical committee of Maharishi Markandeshwar Institute of Medical Science and Research and the study was conducted after taking informed and written consent from the patients.

\section{Inclusion criteria}

All cases of pleural effusion which were admitted in Internal Medicine and Respiratory Medicine wards.

\section{Exclusion criteria}

1. Patients taking antioxidants i.e. Vitamin A, E and C.

2. Patient with known malignancies receiving cytotoxic drugs.

3. Traumatic pleural effusion.

4. Patients on anti-tubercular drugs.

\section{Sample collection and analysis}

The initial evaluation of the patients with pleural effusion consisted of history, physical examination, laboratory investigations and roentgenographic studies. Prior to aspiration, informed and written consent was taken before the thoracentesis was done. Aspiration of samples (pleural fluid) was done after proper analgesic/ sedation (if required) and local anesthesia. Pleural fluid and serum samples were collected from all patients on the day of their hospital admission. All the samples were immediately analysed for biochemical parameters under study.

\section{Methods}

Lipid peroxidation products were quantified by the thiobarbituricacid (TBA) method. In this reaction, the pink colour obtained with MDA (an end product of lipid peroxidation) using TBA was determined at $532 \mathrm{~nm}$ wavelength. Tetramethoxypropane was used as an external standard. ${ }^{[10]}$ SOD was determined by Kakkar et al method, ${ }^{[11]} \mathrm{LDH}$ by modified IFCC method in which rate of oxidation of NADH to NAD was measured as a decrease in absorbance that was proportional to the $\mathrm{LDH}$ activity in the sample ${ }^{[12]}$ and total protein (TPR) was quantified by Biuret method. ${ }^{[13]}$

\section{Statistical analysis}

The data obtained was compiled and analyzed using SPSS 11.5 for Windows version. Means \pm standard deviation were calculated and student t-test was applied to find out significance level. Statistical significance was defined as two-tailed $p<0.05$ for all tests unless otherwise specified. 
Qazi Najeeb, et al.: Malondialdehyde (MDA) and superoxide dismutase (SOD) levels

\section{RESULTS}

Out of 96 cases of pleural effusion, 61 were males and 35 were females. Their mean age was $45.12 \pm 9.23$ years. All the pleural fluid samples obtained from the patients were classified into two groups. Pleural fluid was collected from group-I which consist 48 patients (32 males, 16 females) and from group-II which consists of 48 patients (29 males, 19 females). The classification of pleural fluid according to histo-pathology is summarised in (Table-1). Mean serum levels of MDA, SOD, LDH and TPR in malignant pleural effusion (group-I) were $131.88 \pm 12.17,39.28 \pm 5.28,285.20 \pm 33.06,6.0 \pm 0.67$ and in benign pleural effusion (group-II) were $72.83 \pm 5.58$, $34.35 \pm 3.61,227.69 \pm 10.01,6.13 \pm 0.58$ respectively. In pleural fluid mean levels of MDA, SOD, LDH and TPR

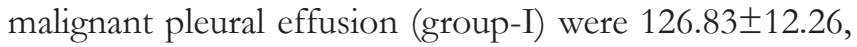
$38.63 \pm 5.67,185.28 \pm 21.48,4.34 \pm 0.84$ and in benign (group-II) were 53.01 $\pm 8.92,32.21 \pm 3.27,120.29 \pm 15.37$, $4.12 \pm 0.47$ respectively as shown in (Table-2). The results indicates there is a significant increase in MDA, SOD and LDH levels in both serum and pleural fluid in group-I patients $\mathrm{p}<0.05$ and there was non-significant increase in TPR levels in group-I in both serum and pleural fluid (Figures 1, 2).

Table 1 Patients with pleural effusion classified according to their histo-pathology

\begin{tabular}{lc}
\hline $\begin{array}{l}\text { Malignant Pleural Effusion } \\
\text { (Group-I) }\end{array}$ & Number of cases \\
\hline Non-small cell carcinoma & 32 \\
Small cell carcinoma & 4 \\
Lymphoma & 2 \\
Metastatic lung carcinoma & 10 \\
Benign Pleural Effusion (Group-II) & \\
Congestive cardiac failure & 10 \\
Pulmonary tuberculosis & 28 \\
Pneumonia & 6 \\
Cirrhosis of liver & 4 \\
\hline
\end{tabular}

Table 2 Depicting mean, standard deviation and significance of pleural fluid and serum levels in two groups

\begin{tabular}{lccc}
\hline Parameters & $\begin{array}{c}\text { Malignant } \\
\text { (Group-I) } \\
\text { mean } \pm \text { SD }\end{array}$ & $\begin{array}{c}\text { Benign } \\
\text { (Group-II) } \\
\text { mean } \pm S D\end{array}$ & $\begin{array}{c}\text { Signifi- } \\
\text { cance } \\
\text { p-value }\end{array}$ \\
\hline Pleural MDA $(\mathrm{nmol} / \mathrm{ml})$ & $126.83 \pm 12.26$ & $53.01 \pm 8.92$ & $<0.001$ \\
Pleural SOD $(\mathrm{U} / \mathrm{ml})$ & $38.63 \pm 5.67$ & $32.21 \pm 3.27$ & $<0.001$ \\
Pleural LDH $(\mathrm{IU} / \mathrm{L})$ & $185.28 \pm 21.48$ & $120.29 \pm 15.37$ & $<0.001$ \\
Pleural TPR $(\mathrm{gm} \%)$ & $4.34 \pm 0.84$ & $4.12 \pm 0.47$ & 0.122 \\
Serum MDA $(\mathrm{nmol} / \mathrm{ml})$ & $131.88 \pm 12.17$ & $72.83 \pm 5.58$ & $<0.001$ \\
Serum SOD $(\mathrm{U} / \mathrm{ml})$ & $39.28 \pm 5.28$ & $34.35 \pm 3.61$ & $<0.001$ \\
Serum LDH $(\mathrm{IU} / \mathrm{L})$ & $285.20 \pm 33.06$ & $227.69 \pm 10.01$ & $<0.001$ \\
Serum TPR $(\mathrm{gm} \%)$ & $6.0 \pm 0.67$ & $6.13 \pm 0.58$ & 0.335 \\
\hline
\end{tabular}

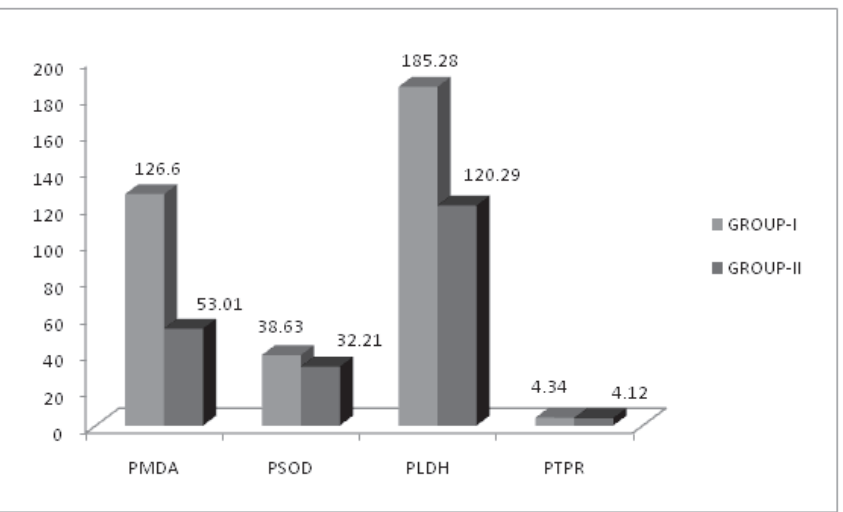

Figure 1. Showing pleural malondialdehyde (PMDA), pleural superoxide dismutase (PSOD), pleural lactate dehydrogenase (PLDH) and pleural total protein (PTPR) levels in group-I and group-II.

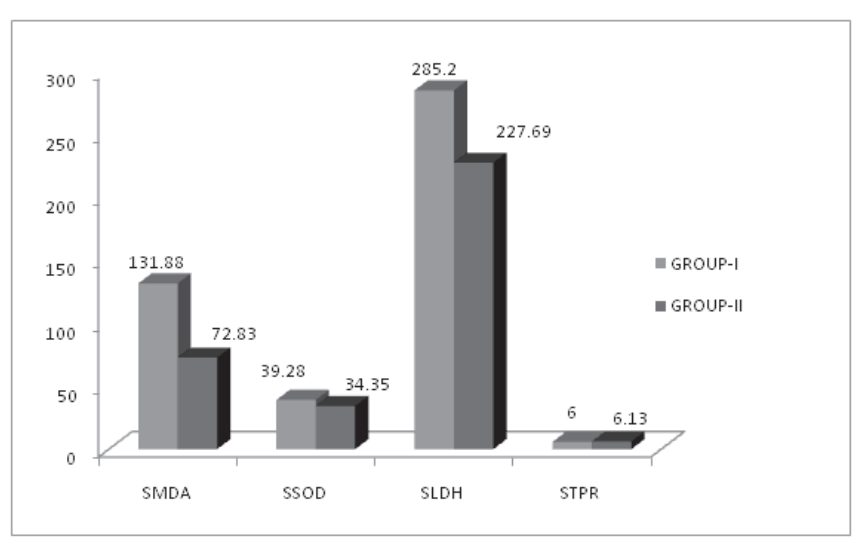

Figure 2. Showing serum malondialdehyde (SMDA), serum superoxide dismutase (SSOD), serum lactate dehydrogenase $(\mathrm{SLDH})$ and serum total protein (STPR) levels in group-I and group-II.

\section{DISCUSSION}

In this prospective study, it was observed that malignant pleural effusions presents as increased levels of oxidative stress (MDA levels) compared to benign effusions. The increased level of oxidative stress in malignant pleural effusion probably represents the increased local production of free radicals. The origin of this local oxidative burst is related to the nature of each disease entity. ${ }^{[14]}$ Oxidants have been shown to play an important role in carcinogenesis; serving not only as tumor initiators but also as tumor promoters and regulators of gene expression. ${ }^{[15]}$ In many diseases free radicals play a very important role. ${ }^{[16]}$ Impairment in the antioxidant system in our body due to reactive oxygen species (ROS) triggers lipid peroxidation and DNA damage which can lead to carcinogenesis. ${ }^{[17]}$ Increased lipid peroxide products in abnormally proliferating cells due to the oxidative damage are thought to be released into the systemic circulation resulting in their increased levels in 
Qazi Najeeb, et al.: Malondialdehyde (MDA) and superoxide dismutase (SOD) levels

serum or pleural fluids in case of cancer patients. ${ }^{[18]}$ In our study, MDA content in malignant pleural fluids was higher than in benign pleural fluids. Earlier reports also described elevated plasma MDA levels in malignant pleural exudates when compared to those of non-malignant effusions. ${ }^{[19,20]}$

Free radicals like superoxide anion are highly reactive and can cause both morphological and functional damage in the cell. ${ }^{[21]}$ The cells protect themselves against oxidative damage by enzymatic and non-enzymatic antioxidant system. Superoxide dismutase is the primary enzymatic antioxidant defence system in the cell. ${ }^{[22]}$ This scavenging enzyme plays an important role in the protection of cell against the potentially harmful effects of superoxide anion generated by a wide variety of biological processes. ${ }^{[23]}$ In our study there is significant increase in SOD activity in group-I (malignant) as compared to group-II (benign). Lizutci et al reported that SOD activity was significantly elevated in cancerous lung tissues when compared with those of normal uninvolved tissues. ${ }^{[2]}$ In another study, increased SOD activity was also determined in serum from patients with ovarian cancer. ${ }^{[25]}$

We also found that there is a statistically significant increase in LDH activity and insignificant increase TPR in serum as well as pleural fluids of group-I (malignant) as compared to group-II (benign).

\section{CONCLUSION}

Elevated MDA levels and increased activities of SOD enzymes were found in malignant pleural fluids when compared to the benign pleural fluids. These results suggest that, in spite of an increase in the activity of SOD, there is an increase in lipid peroxidation products which could reflect the fact that oxidative stress had increased as compared to the capacity of the antioxidants enzymes in pleural fluid. As MDA and SOD levels are significantly increased in malignant effusions, so they might be helpful in differentiating between malignant and benign pleural effusions as compared to previous criteria.

\section{ACKNOWLEDGEMENTS}

The authors express gratitude to the all participants (patients) in this study for their patience and support.

\section{COMPETING INTERESTS}

The authors declare that there were no competing interests associated with this study.

\section{REFERENCES}

1. Das AK, Baruah K. A Study on significance of serum effusion albumin gradient in the differential diagnosis of pleural effusion. $J$ k science 2009; 11(3): 123-6.

2. Ciftci TU, Guney Y, Bilgihan A, Cimen F. The role of Superoxide Dismutase (Sod) activity and Malondialdehyde (Mda) levels in the differentiation of benign-malignant pleural effusion. Ankara University School of Dikimevi Journal of Health Services 2004; 6(2): 39-43.

3. Bircan A, Recep Sutcu R, Gokirmak M, Hicyilmaz H, Akkaya A, Ozturk O. Total antioxidant capacity and C-reactive protein levels in patients with Community-acquired pneumonia. Turk J Med Sci 2008; 38(6): 537-44

4. Gavino VC, Miller JS, Ikharebha SO et al. Effects of polyunsaturated fatty acids and antioxidants on lipid peroxidation in tissue cultures. J Lipid Res 1981; 22: 763-9.

5. Devi GS, Prasad MH, Saraswathi I et al. Free radicals antioxidant enzymes and lipid peroxidation indifferent types of leukemias. Clinica Chimica Acta 2000; 293: 53-62.

6. Kwiatkowska S, Piasecka G, Zieba M, Piotrowski W, Nowak D. Increased serum concentrations of conjugated dienes and malondialdehyde in patients with pulmonary tuberculosis. Respir Med 1999; 93(4): 272-6.

7. Cerutti PA. Oxyradicals and cancer. Lancet 1994; 344: 862-3.

8. Menkes MS, Comstock GW, Vuilleumier JP, Helsing KJ, Rider AA, Brookmeyer R. Serum betacarotene, vitamins $A$ and $E$, selenium and the risk of lung cancer. N Engl J Med 1986; 315: 1250-4.

9. Yamaguchi S, Sakurada S, Nagumo M. Role of intracellular SOD in protecting human leukaemic and cancer cells against superoxide and radiation. Free Radical Biol Med 1994; 17: 389-95.

10. Yagi K. Simple procedure for specific assay of lipid hydroperoxidases in serum or plasma. Free Radical and Antioxidant Protocols 1998; 108: 101-6.

11 Kakkar P, Dos B, Viswanathan PN. A modified spectrophotometric assay of superoxide dismutase. Indian J.Biochem 1984; 21:130-2.

12. Varley $H$, Gowenlock $A H$, Bell $M$. Determination of serum lactate dehydrogenase activity. In:Clinical Biochemistry, 5th Ed. Williams Hieinemanm Medical Books Ltd, London.1980; pp 715-20.

13. Kingsley GR. The direct Biuret method for detection of plasma protein as applied to photoelectric and visual Colorimetry. J Lab Clin Med 1842: 27 $840-5$.

14. Choe N, Tanaka S, Kagan E. Asbestos fibers and interleukin-1 upregulate the formation of reactive nitrogen species in rat pleural mesothelial cells. Am J Respir Cell Mol Biol 1998; 19: 226-36.

15. Upham BL, Wagner JG. Toxicant-induced oxidative stress in cancer Toxicol Sci 2001 64: 1-3.

16. Timothy RR, Sharma HM. Free radicals in health and disease. Indian J Clin Pract 1991; 2: 15-25.

17. Jaruga $\mathrm{P}$, Zastawny $\mathrm{TH}$, Skoleowski $\mathrm{S}$ et al. Oxidation DNA base damage and antioxidant enzyme activities in human lung cancer. FEBS Letters 1994: 341: 59-64.

18. Guyton KZ, Kensler TW. Oxidative mechanism in carcinogenesis. Br Med Bull 1993; 49: 523-44.

19. Vanisree AJ, Syamaladevi CS. Status of lipid peroxidation and antioxidant enzymes in malignant (bronchogenic carcinoma) and non-malignant pleural effusions. Indian Journal of Cancer 1999; 36: 127-34.

20. Hammouda MA, Khalil MM, Salem A. Lipid peroxidation products in pleural fluid for seperation of transudates and exudates. Clinical Chemistry 1995; 41(9): 1314-15

21. Deaciuc IV, D'Souza NB, Sarphie TG, Schmidt J, Hill DB, McClain CJ. Effects of exogenous superoxide anion and nitric oxide on the scavenging function and electron microscopic appearance of the sinusoidal endothelium in the isolated, perfused rat liver. J Hepatol. 1999; 30(2): 213-22.

22. Galleotti T, Masotti L, Borrello S. Oxy-radical metabolism and control of tumour growth. Xenobiotica 1991; 21: 1041-51.

23. Bhuvarahamurthy $V$, Balasubramaniant $M$, Govindasamy $S$. Effect of radiotherapy and chemoradiatherapy on circulating antioxidant system of human uterine cervical carcinoma. Molecular and Cellular Biochemistry 1996; 158: 17-23.

24. Lizuka S. Human manganase-containing superoxide dismutase; immunoassay and contents in lung cancer. Hokkoido Igatu Zasshi 1984 59: 739-49.

25. Taniguchi N. Superoxide dismutase significances in aging, diabetes, ischemia and cancer. Rinshe Boyri 1990; 38: 376-81. 